\title{
Some Evidence of Purchasing Power Parity
}

\author{
Peter S. Sephton*
}

School of Business, Queen's University, Kingston, ON, K7L 3N6, Canada

\begin{abstract}
Empirical support for purchasing power parity is mixed with results dependent on the time frame and countries under examination, the methodology employed, attempts to control for aggregation bias in the data, and whether adjustments are made to account for productivity differences across nations. As a central component of macroeconomic thinking, purchasing power parity is battered and battle-worn. Using methods that allow for breaking means and trends, this research note provides irrefutable evidence in favor of purchasing power parity for a wide range of countries since the late 1800s. The results suggest managers can consider purchasing power parity a long-term anchor around which they can build their strategic plans.
\end{abstract}

Keywords: Real exchange rate, fractional integration, long-memory, purchasing power parity.

\section{INTRODUCTION}

Economists are full of good ideas that sometimes go bad. Our collective forecasting records make weather predictors look like rock-stars, particularly when you consider we have predicted 17 of the last three recessions.... We put decimal points in our forecasts to show we have a sense of humor. We like to speak about the "law of demand" which really is not a law at all. Most economists would probably agree that if we were to have a law, a fundamental principle that is inviolate, it would probably be the idea that when price rises, quantity demanded falls, conditioned of course by our blanket use of ceteris paribus. A close contender to the "law of demand" - if there were ever a theory that we hoped would ring true - might be the principle that in the long-run, nominal exchange rates move to reflect changes in national price levels. Big Mac and Ipod indexes aside, purchasing power parity (PPP) is one of those tenets we love and hate at the same time - and for which we spend considerable time apologizing when the empirical evidence suggests little support for the idea that nominal exchange rates move in response to changes in national price levels.

The purpose of this short note is to provide a new perspective on PPP and to demonstrate that in this context, once structural breaks are allowed, there have been periods during which PPP prevailed. While persistent departures from the law of one price are possible, managers can rely on PPP as an anchor on which to form their long-term strategic plans. The next section provides a quick summary of the concept of fractional integration and provides a rationale for the methodology employed herein. This is followed by a discussion of the empirical results, which provide overwhelming support for PPP. Final remarks follow.

\footnotetext{
*Address correspondence to this author at the School of Business, Queen's University, Kingston, ON, K7L 3N6, Canada; Tel: 613533 3013; Fax: 613 533 6847; E-mail: PSephton@business.queensu.ca
}

\section{MATERIALS AND METHODOLOGY}

Empirical studies on PPP typically examine the temporal properties of nominal exchange rates and national price levels to determine whether exchange rates move when relative prices move. Single equation methods as well as multiple equation cointegration studies, some based on panel data, indicate that a researcher can obtain any answer they like. One would hope that if the theory were true, disparate methods and techniques would all lead to the same conclusion. Unfortunately, unit root and cointegration tests are fraught with difficulties, both in terms of the small sample properties of the tests and estimators, and in terms of the power of the tests to discriminate among competing hypotheses. Implementation issues also cloud the researcher's task, since tests allowing for constants and/or trends, and different approaches to lag length determination (used to purge the tests of contamination from serial correlation) often lead to conflicting inferences. Sephton [1] provides a useful summary of some of this literature.

When one rejects the hypotheses that a series contains a unit root and that the series is stationary, it is common to look for evidence of fractional integration. A fractionally integrated series can be mean reverting but non-covariance stationary and it can mimic the behavior of a non-stationary series if there is sufficient inertia in the data. The fractional differencing operator acts like the factorial operator, with non-integer values. Fractionally integrated series exhibit long-memory, with very long half-lives of shocks and very slow decays in the autocorrelation structure. It might be that real exchange rates are fractionally integrated of an order below one, but above zero, so it is critically important to determine whether real exchange rates are fractionally integrated. If so, the evidence in favor of PPP would be strengthened.

There are many different approaches to estimating and testing for fractional integration; all appear to suffer just as 
much as unit root and stationarity tests from implementation issues, as recently demonstrated by Sephton [1] and Dufrenot et al. [2]. Using different tests and estimators, it is possible to find evidence both in favor and against PPP using long spans of data. It would appear that fractional integration methods are not the panacea we might have hoped for in the search for evidence of PPP.

However, Gil-Alana [3] provides a novel approach to solving this conundrum by allowing for breaking means and trends in a fractionally integrated series. One of the confounding affects on all tests of PPP is how to deal with structural breaks associated with wars, post-war adjustment, and the fixed/flexible exchange rate regimes in place over the last century. It is well known that unit root tests have low power when a stationary series experiences a level shift. One can find, using unit root tests without breaks, results that are at odds with identical techniques that do allow for one, or two breaks during the estimation period. Similar concerns arise when employing tests of fractional integration, with and without breaks. The novel approach here, due to Gil-Alana [3], is to turn the question on its head and find the values of the fractional integration parameters $\left(d_{1}\right.$ and $\left.d_{2}\right)$, assuming one break at period $T_{b}$, that minimize the sum of square residuals over the two sub-sample periods, with the processes following equations (1) and (2), where $\partial_{i}$ denotes the inter-

cepts and $\phi_{i}$ the trend terms across the two subperiods, with $\omega_{t}$ white noise and $L$ the lag operator:

$y_{\mathrm{t}}=\partial_{1}+\phi_{1} t+\varepsilon_{t} \quad(1-\mathrm{L})^{d l} \varepsilon_{t}=\omega_{\mathrm{t}}, t=1, \ldots, T_{b}$

$y_{\mathrm{t}}=\partial_{2}+\phi_{2} t+\varepsilon_{t}(1-\mathrm{L})^{d 2} \varepsilon_{t}=\omega_{t}, t=T_{b}+1, \ldots T$

If $d_{1}$ and $d_{2}$ are less than one, the series is fractionally integrated, with different orders of integration and deterministics before and after the break. The data is allowed to determine the "optimal" degree of fractional integration (up to and including a unit root). Gil-Alana [3] demonstrates that even in small samples (100 observations) this technique works well and identifies the break-dates with precision. Perhaps this approach can be used to provide light into the debate over PPP.

\section{RESULTS}

Sephton [1] argues it is reasonable to examine real exchange rates to determine whether they are stationary series, with such a finding supporting PPP. The idea is that permanent shocks to relative prices must be reflected in permanent shocks to nominal exchange rates, leaving the real exchange rate a stationary 'residual'. Sephton [1] employs the same dataset on 16 countries as Taylor [4] and Lopez, Murray and Papell [5], omitting Argentina, Brazil and Mexico, and extending the data beyond 1996 to 1998. The 16 nations include Australia, Belgium, Canada, Denmark, Finland, France, Germany, Italy, Japan, the Netherlands, Norway, Portugal, Spain, Sweden, Switzerland, and the United Kingdom. All series are expressed as natural logarithms; many span from 1870 until 1998, and real exchange rates were constructed using consumer price indices where available (otherwise GDP deflators were used). Detailed data descriptions can be found in Sephton [1] and the references therein.
The approach first considered here is to allow for one break in the real exchange rate series and search for the degree of fractional integration across the two sub-periods that minimizes the sum of squared residuals. Effectively one chooses the first break point; searches over different values of the degree of fractional integration pre-break and post-break that provide a minimum to the sum of squared residuals; the breakpoint is moved forward one period and the search resumes. Once all potential breakpoints have been considered, the breakpoint associated with the lowest sum of squared residuals is chosen, which is then associated with the values of the fractional integration parameters. This computationally intensive search is relatively straightforward. MATLAB code to implement the procedure with ten percent trimming at each end of the sample is available from the author's website (http://web.business.queensu.ca/faculty/PSephton/PPP).

The first few columns of Table 1 present estimates of the optimal breakpoint and degree of fractional integration whence it is clear that there appears to be very little evidence in favor of PPP. Most estimates suggest real exchange rates were a random walk, with many breakpoints associated with adjustments relating to the two World Wars. It would appear that PPP, as a theory of exchange rate determination, is without merit and should have no role in the manager's toolkit.

However, all is not lost! Why consider only one breakpoint? The Gil-Alana [3] approach can be extended to as many breaks as one would like, although the computational burden does rise significantly as the search is extended beyond one simple break. Towards this end, Table 1 also presents estimates of the optimal breakpoints and degrees of fractional integration when the methods are extended to two breaks (MATLAB code to implement the two-break routine is also available at the author's website). The procedure follows an approach similar to the one break methodology, only now, given the first break, the search involves the choice of a second break that splits the sample into three sub-periods; values of the fractional integration coefficients that minimize the sum of squared residuals are obtained; the first breakpoint is updated, and the search proceeds. Minimizing the total sum of squares leads to the "optimal" breakpoints, as well as the "optimal" values of the degree of fractional integration. The final few columns of Table 1 contain the estimated breakpoints and fractional integration coefficients.

In every case the breakpoints coincide with events in history, for example, inter-War periods during which the construction of national price indices were in flux as national authorities regulated wages and prices, or periods during which exchange rates were set according to Bretton Woods or there were currency and exchange controls in effect.

Consider Italy as an example - in the single-break specification, the real exchange rate is a random walk after 1921 while in the two-break model breaks occur after both World War I and World War II, with the real exchange rate a stationary process during each sub-period. This result highlights the fact that a stationary mean-reverting process may appear to be a random walk when allowance is not made for the correct number of breaks. 
Table 1. Fractional Integration with Breaks

\begin{tabular}{|c|c|c|c|c|c|c|c|c|}
\hline Belgium & 1920 & 1 & 1 & 1907 & 1919 & 0.04 & 0.44 & 0.19 \\
\hline Canada & 1949 & 1 & 1 & 1882 & 1908 & 0 & 0.38 & 1 \\
\hline France & 1986 & 1 & 0 & 1917 & 1934 & 0.11 & 0.09 & 0.32 \\
\hline Germany & 1987 & 1 & 0 & 1912 & 1934 & 0.18 & 0.45 & 1 \\
\hline Italy & 1921 & 0.15 & 1 & 1919 & 1945 & 0.04 & 0.23 & 0.33 \\
\hline Japan & 1980 & 1 & 0.98 & 1930 & 1946 & 0.15 & 0.27 & 0.23 \\
\hline Netherlands & 1950 & 1 & 1 & 1918 & 1934 & 0.19 & 0.64 & 0.73 \\
\hline Sweden & 1950 & 0.89 & 1 & 1918 & 1981 & 0.21 & 0.38 & 0.2 \\
\hline Switzerland & 1987 & 1 & 0 & 1918 & 1934 & 0.29 & 0.7 & 0.66 \\
\hline UK & 1950 & 0.99 & 0.7 & 1949 & 1984 & 0.71 & 1 & 0 \\
\hline
\end{tabular}

Interoccular inspection of Table $\mathbf{1}$ indicates that many singlebreak points are different from those identified in the two-break models. There is no reason, a priori, to expect that the two-break models should include the same breakpoints as the single-break specification since the procedure is aimed at minimizing the sum of squared residuals. If there are truly two mean-shifts but only one is allowed, the search process will not achieve a global minimum. If two breaks are allowed but in fact there has only been one, the procedure should identify only one break as being significant, with the second break right after the first break. Given that result was not obtained for any of the real exchange rates, the results strongly support the view that the two-break specification is more appropriate than the single-break model.

All currencies have exhibited evidence in favor of PPP during the last 120 years, some more so than others. Only in Canada and Germany do real exchange rates suggest evidence against PPP since their second breakpoints, early in the $20^{\text {th }}$ Century. All other currencies indicate there were periods during which PPP held quite well, with real exchange rates mean-reverting over most of the last century.

\section{CONCLUSIONS}

The purpose of this short note was to provide a new view to whether PPP held over the last century. Using a relatively novel approach, the results suggest that there were periods during which all real exchange rates tended to revert to their means, a necessary condition for PPP. The findings indicate that managers taking a long-run view can use the tenets of PPP in their strategic planning insofar as the question of mean-reversion has managerial significance. The fact that the results for Canada and Germany suggest non-stationarity since the early $20^{\text {th }}$ Century suggests that extending the current analysis beyond two breaks may provide additional insight into the temporal behavior of these real exchange rates.

Subsequent work might extend the current analysis beyond 1998 and to higher frequency data. Given the changes in the values of major currencies over the last decade, this would be of particular importance to managers making decisions in an increasingly globalized economy.

\section{ACKNOWLEDGEMENTS}

I thank Luis Gil-Alana for sharing his FORTRAN code and seminar participants at Fordham University for useful comments.

\section{REFERENCES}

[1] Sephton PS. Unit roots and purchasing power parity: Another Kick at the Can. Appl Econ 2008; forthcoming.

[2] Dufrenot G, Lardic S, Mathieu L, Mignon V, Peguin-Feissolle A. Explaining the European exchange rates deviations: Long memory or non-linear adjustment? J Int Fin Mkt Ins Mon 2008; 18(3): 207-15.

[3] Gil-Alana L. Fractional integration and structural breaks at unknown periods of time. JTS Anal 2008; 29(1): 163-85.

[4] Taylor A. A century of purchasing power parity. Rev Econ Stat 2002 84: 139-50.

[5] Lopez C, Murray C, Papell D. State of the Art Unit Root Tests and purchasing power parity. J Money Credit Banking 2005; 37: 361-9. 